Research, Society and Development, v. 10, n.5, e55610515203, 2021

(CC BY 4.0) | ISSN 2525-3409 | DOI: http://dx.doi.org/10.33448/rsd-v10i5.15203

\title{
Associação da síndrome da imunodeficiência humana com o linfoma de não Hodgkin
}

\author{
Association of human immunodeficiency syndrome with non-Hodgkin's lymphoma \\ Asociación del síndrome de inmunodeficiencia humana con linfoma no Hodgkin
}

Recebido: 19/04/2021 | Revisado: 25/04/2021 | Aceito: 03/05/2021 | Publicado: 16/05/2021

Lennara Pereira Mota

ORCID: https://orcid.org/0000-0002-2629-6634

Centro Universitário Maurício de Nassau, Brasil

E-mail: lennaramota@ hotmail.com

Cryshna Letícia Kirchesch

ORCID: https://orcid.org/0000-0002-5866-3216 Universidade Federal de Pelotas, Brasil

E-mail: cryshna.clk@gmail.com

Amadeu Luis de Carvalho Neto

ORCID: https://orcid.org/0000-0001-7726-6120

Universidade Federal do Piaú, Brasil

E-mail: amadeusc.neto@hotmail.com

Josemária Chaves Sipauba Silva

ORCID: https://orcid.org/0000-0003-2285-7497 Centro Universitário Maurício de Nassau, Brasil

E-mail: josemaria_sipauba@hotmail.com

Josefa Angélica Cerqueira Poty

ORCID: https://orcid.org/0000-0002-3838-0833 Centro Universitário UniFacid, Brasil

E-mail: potyjosefa@gmail.com

José Guilherme Férrer Pompeu

ORCID: https://orcid.org/0000-0001-9038-0833 Universidade Federal do Piauí, Brasil

E-mail: gpompeu8@gmail.com

Raquel Gomes Gonzalez Aleluia

ORCID: https://orcid.org/0000-0003-3514-1519 Centro Universitário UniFacid, Brasil E-mail: raquellgomez86@gmail.com

Mylena Silva da Silva

ORCID: https://orcid.org/0000-0002-4872-3131 Universidade Federal do Piauí, Brasil E-mail: mylenaa_silvaa@hotmail.com

Rodrigo Campelo de Moura Fé

ORCID: https://orcid.org/0000-0003-4776-078X Instituto de Ensino Superior do Vale do Parnaíba, Brasil E-mail: rodrigocmourafe@hotmail.com

Luiz Eduardo Batista da Silva

ORCID: https://orcid.org/0000-0002-7225-1664 Instituto de Ensino Superior do Vale do Parnaíba, Brasil E-mail: Luiz1eduardo@hotmail.com

Edmilson Alves de Carvalho Neto

ORCID: https://orcid.org/0000-0001-5702-2954 Instituto de Ensino Superior do Vale do Parnaíba, Brasil E-mail: edmilsonacn@hotmail.com

Nerley Pacheco Mesquita

ORCID: https://orcid.org/0000-0001-8086-3815 Universidade Estadual do Piauí, Brasil E-mail: nerleymesquita10@gmail.com

Mirian Nascimento Rabelo

ORCID: https://orcid.org/0000-0003-4843-2251 Universidade Federal do Piauí, Brasil E-mail: Mirian.rabelo@hotmail.com

Anna Carmela Araujo Benoliel Vasconcelos ORCID: https://orcid.org/0000-0002-1126-6766

Universidade ITPAC porto nacional, Brasil

E-mail: anacarmelaaraujo@hotmail.com

João Vitor Messias Esperandio

ORCID: https://orcid.org/0000-0003-0184-4531 Instituto Tocantinense Presidente Antonio Carlos, Brasil

E-mail: jvmessiasesperandio@hotmail.com 


\author{
Maria Rosa de Lima Sousa \\ ORCID: https://orcid.org/0000-0002-5390-4535 \\ Faculdade de Medicina de Marília, Brasil \\ E-mail: mrosa-lima@hotmail.com \\ Stefânia Araújo Pereira \\ ORCID: https://orcid.org/0000-0001-5288-8193 \\ Universidade Estadual do Piauí, Brasil \\ E-mail: stefania.rillys@gmail.com
}

\begin{abstract}
Resumo
O HIV é o vírus da imunodeficiência adquirida, caracterizado pela replicação viral e redução dos linfócitos T CD4 +. Faz parte do gênero Lentivírus e da família Retroviral. Além disso, também pode causar alterações imunológicas e infecções oportunistas, levando ao desenvolvimento da síndrome da imunodeficiência adquirida (SIDA), que é a manifestação clínica avançada do vírus. O linfoma não-Hodgkin é considerado o segundo câncer mais comum entre os pacientes com SIDA. O trabalho tem por objetivo expor as principais causas da associação da Síndrome da Imunodeficiência Adquirida com o Linfoma de não Hodgkin. Trata-se de uma revisão bibliográfica de caráter qualitativo que se baseia na produção científica a partir de estudos já publicados. Desde a primeira descrição da Síndrome da Imunodeficiência Adquirida, sua associação com o aumento do risco da formação de múltiplos tumores tornou-se clara. A própria definição de SIDA, além da relação com várias infecções oportunistas, também inclui certos tipos de tumores, como (linfoma não-Hodgkin, sarcoma de Kaposi e câncer cervical). Um dos canceres mais comuns associados a SIDA é o linfoma não-Hodgkin, uma neoplasia que afeta o sistema linfático dos pacientes e que apresenta um prognóstico ruim e uma expectativa de vida baixa para esses pacientes. É bastante comum pacientes com SIDA com manifestações clínicas inespecíficas não realizem o tratamento e só descobrirem a infecção durante o tratamento para os linfomas.
\end{abstract}

Palavras-chave: Neoplasias; Linfoma; Sistema imunológico; SIDA.

\begin{abstract}
HIV is the acquired immunodeficiency virus, characterized by viral replication and reduction of CD4 + T lymphocytes. It is part of the genus Lentivirus and the Retroviral family. In addition, it can also cause immunological changes and opportunistic infections, leading to the development of acquired immunodeficiency syndrome (AIDS), which is the advanced clinical manifestation of the virus. Non-Hodgkin's lymphoma is considered the second most common cancer among AIDS patients. The work aims to expose the main causes of the association of Acquired Immunodeficiency Syndrome with Non-Hodgkin's Lymphoma. This is a qualitative bibliographic review that is based on scientific production based on studies that have already been published. Since the first description of the Acquired Immunodeficiency Syndrome, its association with the increased risk of forming multiple tumors has become clear. The very definition of AIDS, in addition to the relationship with various opportunistic infections, also includes certain types of tumors, such as (non-Hodgkin's lymphoma, Kaposi's sarcoma and cervical cancer). One of the most common cancers associated with AIDS is non-Hodgkin's lymphoma, a neoplasm that affects the lymphatic system of patients and that has a poor prognosis and a low life expectancy for these patients. It is quite common for AIDS patients with nonspecific clinical manifestations not to undergo treatment and only discover the infection during treatment for lymphomas.
\end{abstract}

Keywords: Neoplasms; Lymphoma; Immune system; AIDS.

\title{
Resumen
}

El VIH es el virus de la inmunodeficiencia adquirida, que se caracteriza por la replicación viral y la reducción de los linfocitos T CD4 +. Es parte del género Lentivirus y la familia Retroviral. Además, también puede causar cambios inmunológicos e infecciones oportunistas, lo que lleva al desarrollo del síndrome de inmunodeficiencia adquirida (SIDA), que es la manifestación clínica avanzada del virus. El linfoma no Hodgkin se considera el segundo cáncer más común entre los pacientes con SIDA. El trabajo tiene como objetivo exponer las principales causas de la asociación del síndrome de inmunodeficiencia adquirida con el linfoma no Hodgkin. Se trata de una revisión bibliográfica cualitativa que se basa en la producción científica a partir de estudios ya publicados. Desde la primera descripción del síndrome de inmunodeficiencia adquirida, se ha hecho evidente su asociación con el aumento del riesgo de formación de múltiples tumores. La propia definición de SIDA, además de la relación con diversas infecciones oportunistas, también incluye ciertos tipos de tumores, como (linfoma no Hodgkin, sarcoma de Kaposi y cáncer de cuello uterino). Uno de los cánceres más comunes asociados al sida es el linfoma no Hodgkin, una neoplasia que afecta el sistema linfático de los pacientes y que tiene un mal pronóstico y una baja esperanza de vida para estos pacientes. Es bastante común que los pacientes con SIDA con manifestaciones clínicas inespecíficas no se sometan a tratamiento y solo descubran la infección durante el tratamiento de los linfomas.

Palabras clave: Neoplasias; Linfoma; Sistema inmunológico; SIDA. 


\section{Introdução}

A infecção pelo vírus da imunodeficiência humana (HIV) é um importante problema de saúde pública em todo o mundo. Isso se deve principalmente à sua transmissibilidade e capacidade de tornar os indivíduos suscetíveis a outras infecções e, gradativamente, levar à morte (Cruz, 2020).

O HIV é o vírus da imunodeficiência adquirida, caracterizado pela replicação viral e redução dos linfócitos T CD4 +. Faz parte do gênero Lentivírus e da família Retroviral. Além disso, também pode causar alterações imunológicas e infecções oportunistas, levando ao desenvolvimento da síndrome da imunodeficiência adquirida (SIDA), que é a manifestação clínica avançada do vírus (Lopes et al., 2019).

Com a introdução da terapia antirretroviral oral combinada (HAART) em 1996, a incidência de cânceres que definem SIDA diminuiu, enquanto a frequência relativa de cânceres que não definem SIDA aumentou. Embora a imunodeficiência seja uma característica comum compartilhada pelos dois grupos acima, os efeitos apenas do HIV, a idade e o uso de medicamentos anti-retrovirais sempre foram controversos (Freitas et al., 2017).

A terapia antirretroviral (TARV) altamente ativa e inibidores de protease podem aumentar a taxa de sobrevivência de pacientes soropositivos devido à inibição da replicação do vírus, melhorando assim sua qualidade de vida. O Brasil é o primeiro país da América Latina a incluir este padrão a partir de 2017. Em janeiro de 1999, o medicamento Dolutegravir entrou no campo do tratamento da SIDA e atualmente é considerado o melhor medicamento para o tratamento do HIV. A Organização Mundial da Saúde (OMS) o elogiou durante a Conferência Internacional de SIDA (Lopes et al., 2019).

Sem tratamento, a infecção pelo vírus da imunodeficiência humana (HIV) pode levar à imunossupressão. Isso se deve à capacidade do vírus de invadir células do sistema imunológico (principalmente células T CD4 +) e depois se reproduzir e sobreviver. Quando esse mecanismo não é revertido, o resultado inevitável é a Síndrome da Imunodeficiência Adquirida e os pacientes começam a desenvolver doenças secundárias, como infecções oportunistas e câncer (Da Silva Araújo et al.,2021).

O aumento da expectativa de vida é um ganho para os portadores do HIV, mas ao longo dos anos, as pessoas perceberam que esse aumento na expectativa de vida também promove o acúmulo de inflamação sistêmica, mutações somáticas e epigenéticas. Mudanças relacionadas à carcinogênese aumentam a incidência de tumores não relacionados à síndrome da imunodeficiência adquirida, como câncer anal, câncer de fígado e câncer de pulmão (Costa et al., 2020).

O linfoma não-Hodgkin é considerado o segundo câncer mais comum entre os pacientes com SIDA. Sua forma clínica sistêmica associada ao vírus da imunodeficiência humana é quase sempre altamente maligna. O envolvimento do sistema nervoso central é muito comum em pacientes com este tipo de linfoma (Fonseca Marrero et al., 2019).

Os sintomas característicos do linfoma ocorrem de várias maneiras. O paciente pode apresentar sintomas sistêmicos, como febre, sudorese e perda de peso de mais de 10\%, sem causa óbvia em 6 meses, e uma história de malignidade, que é obviamente um sintoma inespecífico para o diagnóstico da doença. Alguns pacientes podem ser assintomáticos e inesperadamente encontrar linfonodos aumentados durante os exames clínicos ou radiológicos (Lima, 2019).

O linfoma não Hodgkin (LNH) é um tumor primário derivado de linfócitos, manifestado como tumores sólidos de linfonodos e estruturas orofaríngeas, baço, fígado, submucosa gastrointestinal, medula óssea e pulmões. Independentemente do tipo de tumor, todas as formas de linfoma podem se espalhar para os tecidos do sistema fagocítico mononuclear. Em estágios mais avançados, o envolvimento do sangue pode produzir quadros semelhantes às da leucemia (Petroianu et al., 2020).

O trabalho tem por objetivo expor as principais causas da associação da Síndrome da Imunodeficiência Adquirida com o Linfoma de não Hodgkin. 
Research, Society and Development, v. 10, n.5, e55610515203, 2021

(CC BY 4.0) | ISSN 2525-3409 | DOI: http://dx.doi.org/10.33448/rsd-v10i5.15203

\section{Métodos}

Trata-se de uma revisão bibliográfica de caráter qualitativo que se baseia na produção científica a partir de estudos já publicados. A busca pelos textos foi realizada a partir das seguintes palavras-chaves indexadas no DECS (Descritores em Ciências da Saúde): "Neoplasias"; "Linfoma"; "Sistema Imunológico" e "SIDA" nas plataformas Scientific Electronic Library Online e Biblioteca Virtual em Saúde (BVS).

Os critérios de inclusão foram pesquisas científicas publicadas de 2017 a 2021, publicados no idioma português, inglês e espanhol, que atendiam ao problema da pesquisa: Quais as causas para a associação da Síndrome da Imunodeficiência Adquirida com o Linfoma de não Hodgkin? Os critérios de exclusão foram trabalhos científicos com apenas resumos disponíveis, publicações duplicadas, artigos de relato de experiência, reflexivo, editoriais, comentários e cartas ao editor.

A partir do problema de pesquisa foram selecionados artigos publicados em periódicos nacionais e internacionais escolhidos a partir de levantamento realizado por meios dos descritores na biblioteca virtual Scientific Electronic Library Online, Biblioteca Virtual em Saúde e dissertações e teses.

Os artigos foram selecionados para leitura e foram incluídos na análise quantitativa artigos que se enquadravam no tema proposto do trabalho.

\section{Resultados e Discussão}

A Figura 1 ilustra os resultados deste trabalho que foram obtidos através da análise quantitativa de publicações sobre a associação da Síndrome da Imunodeficiência Adquirida com o Linfoma de não Hodgkin na base de dados Scientific Electronic Library Online e Biblioteca Virtual em Saúde. 
Research, Society and Development, v. 10, n.5, e55610515203, 2021

(CC BY 4.0) | ISSN 2525-3409 | DOI: http://dx.doi.org/10.33448/rsd-v10i5.15203

Figura 1: Fluxograma que apresenta o processo de seleção das publicações de SIDA e Linfoma de não Hodgkin, Teresina, Brasil, 2021.

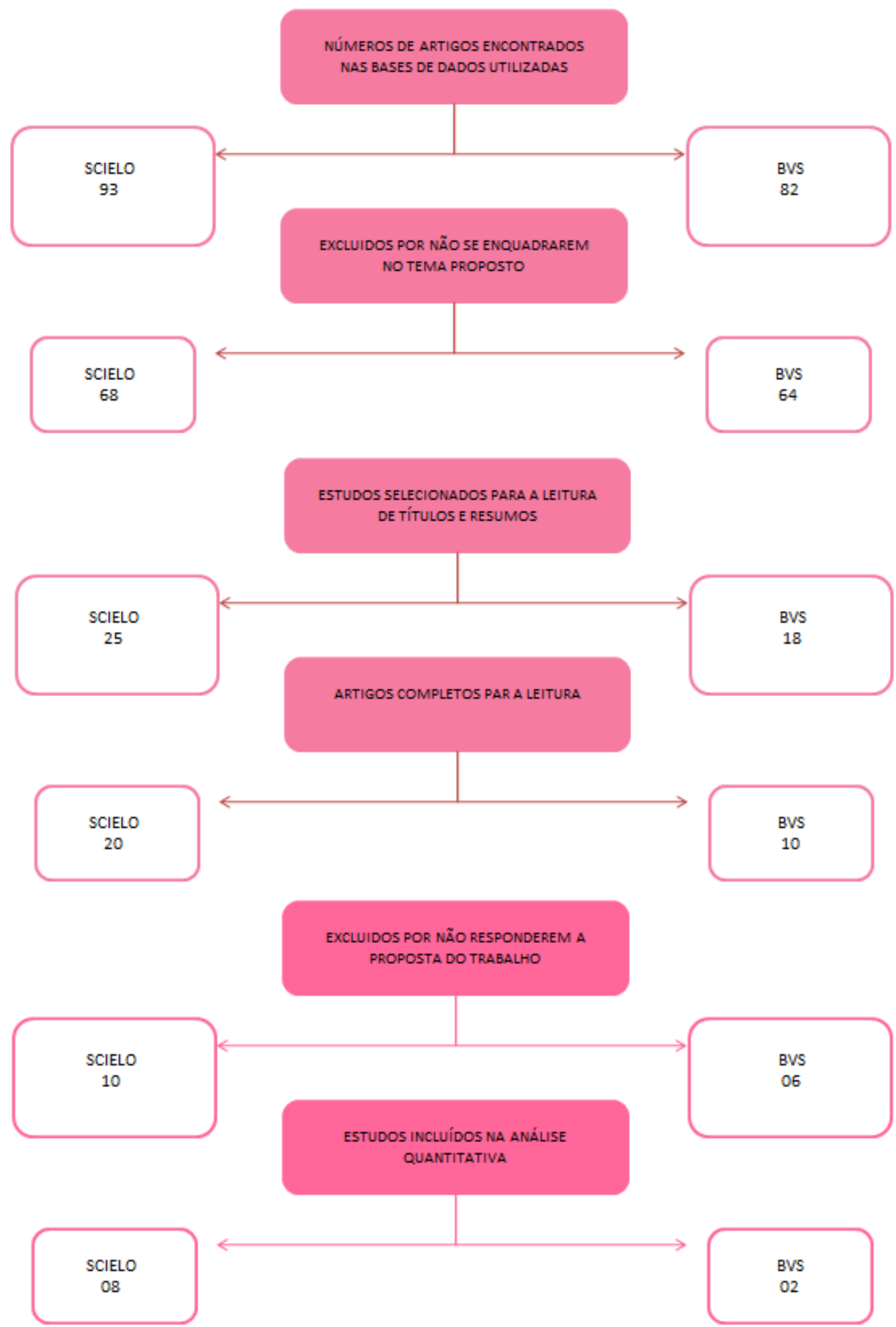

Fonte: Elaborado pelos autores. 
Os resultados deste trabalho foram obtidos através da análise quantitativa de publicações sobre SIDA e Linfoma de não Hodgkin encontrados nas bases de dados Scientific Electronic Library Online e Biblioteca Virtual em Saúde obtendo 93 artigos na Scielo e 82 artigos na BVS. Foram selecionados para a leitura de títulos e resumos o total de 25 e 18 artigos respectivamente e excluídos 68 artigos da Scielo e 64 da BVS por não se enquadrarem no tema proposto. Foi realizada a leitura completa de 20 artigos da Scielo e 10 artigos da BVS, onde 12 da Scielo e 8 da BVS não responderam a proposta do trabalho. Foram incluídos na análise quantitativa 9 artigos da Scielo e 2 artigos da BVS entre os anos de 2017 a 2021.

Quadro 1. Principais títulos e objetivos dos artigos utilizados na pesquisa, Teresina, Brasil, 2021.

\begin{tabular}{|c|c|c|}
\hline $\begin{array}{l}\text { AUTOR / ANO DE } \\
\text { PUBLICAÇÃO }\end{array}$ & TÍTULO & OBJETIVO \\
\hline $\begin{array}{l}\text { Costa et al., } \\
\quad 2020 .\end{array}$ & $\begin{array}{l}\text { Risco de Câncer em Pacientes que Vivem com } \\
\text { HIV/Aids: Revisão Sistemática. }\end{array}$ & $\begin{array}{c}\text { Analisar diferentes fatores de risco para câncer do tipo } \\
\text { não definidor na população HIV positiva, por meio da } \\
\text { seleção de estudos de coorte realizados em diferentes } \\
\text { Regiões do mundo. }\end{array}$ \\
\hline $\begin{array}{l}\text { Cruz, } \\
2020 .\end{array}$ & $\begin{array}{l}\text { Cancro e terapêutica prolongada com ART em } \\
\text { indivíduos seropositivos com HIV. }\end{array}$ & $\begin{array}{l}\text { Associar o uso de ART e a diminuição ou } \\
\text { aumento de determinados tipos de cancros e HIV. }\end{array}$ \\
\hline $\begin{array}{l}\text { Da Silva Araújo et al., } \\
\qquad 2021 .\end{array}$ & $\begin{array}{l}\text { Linfoma de Hodgkin em Pacientes HIV Positivo } \\
\text { em Uso de Antirretrovirais de Alta Efetividade }\end{array}$ & $\begin{array}{l}\text { Identificar casos de linfoma de Hodgkin em pacientes } \\
\text { HIV+ em uso dos antirretrovirais de alta efetividade. }\end{array}$ \\
\hline $\begin{array}{l}\text { Fonseca Marrero et al., } \\
\qquad 2019 .\end{array}$ & $\begin{array}{l}\text { Apresentação atípica de linfoma não Hodgkin } \\
\text { em um paciente com AIDS. }\end{array}$ & $\begin{array}{l}\text { O objetivo deste artigo é descrever um caso incomum de } \\
\text { um paciente HIV positivo, com linfoma não-Hodgkin } \\
\text { difuso de grandes células B. }\end{array}$ \\
\hline $\begin{array}{l}\text { Freitas et al., } \\
\qquad 2017 .\end{array}$ & $\begin{array}{l}\text { Perfil epidemiologico dos pacientes infectados } \\
\text { pelo hiv com e sem cancer em um hospital } \\
\text { publico na baixada santista - SP - Brasil. }\end{array}$ & $\begin{array}{l}\text { Avaliar o perfil epidemiológico dos pacientes infectados } \\
\text { pelo HIV com câncer. }\end{array}$ \\
\hline $\begin{array}{l}\text { Lacet, } \\
2020 .\end{array}$ & $\begin{array}{l}\text { Qual o significado clínico-patológico da } \\
\text { imunoexpressão de CD20 no linfoma de } \\
\text { Hodgkin clássico? }\end{array}$ & $\begin{array}{l}\text { Investigar a imunoexpressão de CD20 e de marcadores } \\
\text { do microambiente tumoral no LHc, visando analisar as } \\
\text { interfaces entre esses parâmetros e os aspectos clínico- } \\
\text { morfológicos de interesse da onco-hematopatologia. }\end{array}$ \\
\hline $\begin{array}{l}\text { Lima, } \\
2019 .\end{array}$ & $\begin{array}{l}\text { Uso de inibidores PI3K no tratamento do } \\
\text { linfoma não-Hodgkin: Uma revisão concisa }\end{array}$ & $\begin{array}{l}\text { Analisar e discutir os avanços terapêuticos mais recentes } \\
\text { para tratamento do LNH, com ênfase nos inibidores de } \\
\text { quinase, particularmente, os inibidores da via PI3K. }\end{array}$ \\
\hline $\begin{array}{l}\text { Lopes, } \\
2019 .\end{array}$ & $\begin{array}{l}\text { Aspectos epidemiológicos e clínicos de } \\
\text { pacientes infectados por HIV. }\end{array}$ & $\begin{array}{l}\text { Tem como finalidade contribuir com a atualização acerca } \\
\text { do tema, abordando sobre agente etiológico, } \\
\text { epidemiologia, fisiopatologia da doença, perfil do } \\
\text { hemograma do paciente acometido com o vírus e o } \\
\text { tratamento. }\end{array}$ \\
\hline $\begin{array}{l}\text { Petroianu et al., } \\
\quad 2020 .\end{array}$ & $\begin{array}{c}\text { Comparação etiopatogênica, epidemiológica e } \\
\text { clinicoterapêutica de linfoma não Hodgkin e } \\
\text { sarcoma de Kaposi. }\end{array}$ & $\begin{array}{l}\text { Avaliar características clínicas dos LNH e SK, } \\
\text { relacionando fatores etiopatogênicos mútuos. }\end{array}$ \\
\hline $\begin{array}{l}\text { Pinto Neto et al., } \\
2021 .\end{array}$ & $\begin{array}{c}\text { Protocolo brasileiro para Infecções Sexualmente } \\
\text { Transmissíveis 2020: infecção pelo HIV em } \\
\text { adolescentes e adultos. }\end{array}$ & $\begin{array}{c}\text { Analisar o protocolo brasileiro para Infecções } \\
\text { Sexualmente Transmissíveis de 2020, em especial a } \\
\text { infecção pelo HIV. }\end{array}$ \\
\hline $\begin{array}{l}\text { Rodrigues, } \\
2019 .\end{array}$ & $\begin{array}{c}\text { Linfoma plasmablástico em paciente com } \\
\text { infecção pelo vírus da imunodeficiência } \\
\text { humana. }\end{array}$ & $\begin{array}{l}\text { Dada a escassez de literatura, relatou-se o caso clínico de } \\
\text { uma paciente do sexo feminino com infecção pelo HIV e } \\
\text { diagnóstico confirmado de linfoma plasmablástico. }\end{array}$ \\
\hline
\end{tabular}

Fonte: SCIELO e BVS.

Desta forma, foi possível listar os principais resultados e conclusões dos estudos publicados na literatura, conforme o Quadro 2. 
Research, Society and Development, v. 10, n.5, e55610515203, 2021

(CC BY 4.0) | ISSN 2525-3409 | DOI: http://dx.doi.org/10.33448/rsd-v10i5.15203

Quadro 2. Resultados e conclusões dos artigos utilizados, Teresina, Brasil, 2021.

\begin{tabular}{|c|c|c|}
\hline AUTOR / ANO & RESULTADOS & CONCLUSÕES \\
\hline $\begin{array}{l}\text { Costa et al., } \\
\quad 2020 .\end{array}$ & $\begin{array}{l}\text { Os cânceres não definidores, que representam } \\
\text { maior incidência entre a população HIV positiva, } \\
\text { são o de pulmão, colorretal, cervical, de vagina e } \\
\text { útero, gástrico, linfoma de Hodgkin e de fígado. }\end{array}$ & $\begin{array}{c}\text { Os estudos demonstram risco aumentado para } \\
\text { diversos tipos de câncer não definidores da aids, } \\
\text { o que nos leva a um novo paradigma, voltado } \\
\text { não somente para o controle do HIV, mas } \\
\text { também para a detecção precoce e tratamento } \\
\text { oportuno, a fim de minimizar as morbidades e } \\
\text { aumentar a expectativa de vida desses } \\
\text { indivíduos. }\end{array}$ \\
\hline $\begin{array}{l}\text { Cruz, } \\
2020 .\end{array}$ & $\begin{array}{l}\text { Sem a ART, a progressiva diminuição de linfócitos } \\
\text { T CD4+e o aumento da imunodeficiência contribui } \\
\text { para o aparecimento de infeções oportunistas, } \\
\text { caraterísticas da evolução da infeção para SIDA, } \\
\text { que pode culminar na morte do hospedeiro. Um das } \\
\text { indicações de SIDA, é quando a contagem de } \\
\text { linfócitos T CD4+, é inferior a } 200 \text { células } / \mathrm{mm} 3 \text {. }\end{array}$ & $\begin{array}{l}\text { Com o estudo da ART e dos seus mecanismos } \\
\text { de ação, verifica-se que em determinados casos } \\
\text { de cancro, como os ADCs, a ART possui um } \\
\text { efeito protetor contra o este mas, em } \\
\text { contrapartida, os NNRTIs e os PIs, parecem } \\
\text { estar relacionados com incidências elevadas em } \\
\text { NADCs, como o HL ou o cancro anal. }\end{array}$ \\
\hline $\begin{array}{l}\text { Da Silva Araújo et al., } \\
2021 .\end{array}$ & $\begin{array}{c}\text { Foi identificado um total de } 21 \text { cânceres não } \\
\text { definidores de SIDA. Destes, os mais comuns } \\
\text { foram o câncer de pele com } 14,3 \% \text { (3); seguido do } \\
\text { câncer de mama com 9,5\% (2); linfoma de Hodgkin } \\
\text { com 9,5\% (2); e o câncer de estômago com } 9,5 \% \\
\text { (2) dos casos. }\end{array}$ & $\begin{array}{c}\text { Os dados obtidos no presente estudo colocam o } \\
\text { linfoma de Hodgkin em segundo lugar entre os } \\
\text { cânceres não definidores de SIDA encontrados. } \\
\text { Contudo, ao considerar o baixo número de } \\
\text { casos, resultante das limitações da pesquisa, } \\
\text { essas informações não permitem concluir sobre } \\
\text { a real quantidade de linfomas de Hodgkin entre } \\
\text { os demais cânceres não definidores de SIDA } \\
\text { ocorridos em pacientes HIV+ na localidade, } \\
\text { tampouco estimar a participação do HIV, carga } \\
\text { viral, condição imunológica e coinfecções como } \\
\text { fatores de risco. }\end{array}$ \\
\hline $\begin{array}{l}\text { Fonseca Marrero et al., } \\
2019 .\end{array}$ & $\begin{array}{l}\text { Em sua forma típica, a infecção pelo HIV evolui } \\
\text { lentamente, com um período de longa latência } \\
\text { clínica, geralmente anos, desde o momento da } \\
\text { infecção primária até o aparecimento dos primeiros } \\
\text { sintomas. HAART modificou o espectro clínico e } \\
\text { prognóstico de infecção, controlando a replicação } \\
\text { viral e prevenindo a progressão da doença. } \\
\text { Atualmente, a maioria dos pacientes infectados } \\
\text { com HIV-1 nos quais a doença progride para a fase } \\
\text { de AIDS são aqueles que são diagnosticados } \\
\text { tardiamente ou não são aderir à HAART. }\end{array}$ & $\begin{array}{c}\text { Conclui-se que é necessário considerar o } \\
\text { diagnóstico de linfoma não Hodgkin em } \\
\text { pacientes com AIDS e paralisia do terceiro } \\
\text { nervo craniano, a fim de fazer um diagnóstico } \\
\text { precoce e iniciar o tratamento em tempo hábil } \\
\text { devido à rápida evolução e ao mau prognóstico } \\
\text { da doença. }\end{array}$ \\
\hline $\begin{array}{l}\text { Freitas et al., } \\
\qquad 2017 .\end{array}$ & $\begin{array}{l}\text { Houve predomínio nas duas populações estudadas } \\
\text { do sexo masculino, raça branca e faixa etária de } 40 \\
\text { a } 50 \text { anos, com media de } 46 \text { anos. Em ambos os } \\
\text { grupos de pacientes infectados pelo HIV ou não; } \\
\text { não houve diferença estatisticamente significante } \\
\text { das células T CD4 Nadir no momento do } \\
\text { recebimento do diagnóstico de câncer, (teste de } \\
\text { Fisher) } \mathrm{P}=0,07 \text {. }\end{array}$ & $\begin{array}{l}\text { Os pacientes infectados pelo HIV com câncer } \\
\text { apresentaram idade maior que } 40 \text { anos, } \\
\text { contagem de células T CD4 maiores que } 200 \\
\text { células/mm3, } 44.5 \% \text { dos cânceres não } \\
\text { relacionados ao HIV. Os cânceres mais comuns } \\
\text { são os linfomas não Hodgkin, Sarcoma de } \\
\text { Kaposi, câncer de Bexiga, câncer de Pulmão, } \\
\text { Colo de útero e câncer de mama. }\end{array}$ \\
\hline $\begin{array}{l}\text { Lacet, } \\
2020 .\end{array}$ & $\begin{array}{c}\text { O fenótipo CD20-positivo foi encontrado em } 45 \\
(25,9 \%) \text { do total de } 174 \text { pacientes com material } \\
\text { disponível. Pacientes CD20-positivos nas células } \\
\text { neoplásicas tendem a se curar antes, } \\
\text { particularmente aqueles com menos de } 10,5 \\
\text { células/CGA (p=0,037). À morfologia, a chance de } \\
\text { um caso ser CD20-positivo é maior quando se tem } \\
\text { granuloma ( } \mathrm{p}=0,034, \text { IC } 95 \% \text { 1,166-50,301). }\end{array}$ & $\begin{array}{l}\text { Há uma associação direta da positividade para } \\
\text { CD20 nas células neoplásicas e no } \\
\text { micromabiente do LHc a uma melhor evolução } \\
\text { clínica. Há também melhor prognóstico } \\
\text { naqueles pacientes com ausência de } \\
\text { imunoexpressão de PD-1, menor número de } \\
\text { plasmócitos e menor densidade vascular. }\end{array}$ \\
\hline $\begin{array}{l}\text { Lima, } \\
2019 .\end{array}$ & $\begin{array}{l}\text { O LNH abrange um espectro de distúrbios } \\
\text { linfoproliferativos e desfechos clínicos variados, } \\
\text { espelhando frequentemente sua célula de origem, } \\
\text { variando de linfomas foliculares indolentes a } \\
\text { doenças agressivas. }\end{array}$ & $\begin{array}{l}\text { O LNH ainda é um desafio tanto quanto para } \\
\text { tratamento quanto para diagnóstico, já que, } \\
\text { como foi visto, ele se justapõe em relação às } \\
\text { leucemias e seus sintomas são usualmente } \\
\text { comuns a outras comorbidades. }\end{array}$ \\
\hline
\end{tabular}




\begin{tabular}{|c|c|c|}
\hline $\begin{array}{l}\text { Lopes, } \\
2019 .\end{array}$ & $\begin{array}{c}\text { A proporção de pessoas vivendo com HIV } \\
\text { diagnosticadas aumentou em 18\%, passando de } \\
71 \% \text { em } 2012 \text { para } 84 \% \text { em 2016. Nos primeiros } \\
\text { seis meses de 2017, o relatório aponta que quase } 35 \\
\text { mil pessoas iniciaram terapia antirretroviral } \\
\text { (TARV). }\end{array}$ & $\begin{array}{l}\text { O avanço em diagnóstico e tratamento de } \\
\text { pacientes infectados pelo HIV no Brasil, nos } \\
\text { últimos anos, é consideravelmente positivo. }\end{array}$ \\
\hline $\begin{array}{l}\text { Petroianu et al., } \\
2020 .\end{array}$ & $\begin{array}{c}\text { A idade variou entre } 15 \text { e } 87 \text { anos para o LNH e } 25 \\
\text { a } 54 \text { anos para o SK, mas a idade dos pacientes com } \\
\text { LNH associado com o HIV não ultrapassou } 34 \\
\text { anos. A proporção homem: mulher foi de } 1,8: 1 \text { para } \\
\text { o LNH, enquanto SK foi registrado apenas em } \\
\text { homens. }\end{array}$ & $\begin{array}{l}\text { A maioria dos pacientes portadores de HIV } \\
\text { descobriram a soropositividade durante } \\
\text { propedêutica para LNH e SK, sem } \\
\text { manifestações clínicas de AIDS. }\end{array}$ \\
\hline $\begin{array}{l}\text { Pinto Neto et al., } \\
2021 .\end{array}$ & $\begin{array}{l}\text { Os objetivos do tratamento antirretroviral são } \\
\text { reduzir a morbidade e mortalidade e prevenir a } \\
\text { transmissão do HIV para outras pessoas. Para } \\
\text { atingir esses objetivos, o tratamento deve resultar } \\
\text { em supressão máxima do HIV. Desse modo, a } \\
\text { adesão ao tratamento é condição essencial para o } \\
\text { seu sucesso e deve ser discutida desde a primeira } \\
\text { consulta. }\end{array}$ & $\begin{array}{c}\text { A TARV deve ser iniciada uma vez } \\
\text { estabelecido o diagnóstico da infecção pelo } \\
\text { HIV, independentemente de critérios clínicos e } \\
\text { imunológicos. Muitas pessoas têm evolução } \\
\text { fatal sem nunca terem sequer iniciado o } \\
\text { tratamento, apesar do acesso universal à terapia } \\
\text { no país. }\end{array}$ \\
\hline Rodrigues,2019. & $\begin{array}{l}\text { O linfoma plasmablástico, em meio aos outros tipos } \\
\text { de LNH, é a manifestação linfoproliferativa com } \\
\text { menor incidência, sendo quase exclusiva em } \\
\text { pacientes com infecção pelo HIV. }\end{array}$ & $\begin{array}{l}\text { Entre os linfomas não Hodgkin, o linfoma } \\
\text { plasmablástico é a manifestação } \\
\text { linfoproliferativa menos comum e que ocorre } \\
\text { quase exclusivamente em pacientes com } \\
\text { infecção pelo HIV. }\end{array}$ \\
\hline
\end{tabular}

Fonte: SCIELO e BVS.

Baseando-se nos resultados e conclusões dos artigos utilizados, pode-se observar que desde a primeira descrição da Síndrome da Imunodeficiência Adquirida, sua associação com o aumento do risco da formação de múltiplos tumores tornou-se clara. A própria definição de SIDA, além da relação com várias infecções oportunistas, também inclui certos tipos de tumores, como (linfoma não-Hodgkin, sarcoma de Kaposi e câncer cervical). Hoje em dia, está bem documentado que pacientes infectados pelo HIV e indivíduos imunossuprimidos após o transplante de órgãos sólidos têm um risco aumentado de desenvolver tumores malignos. Esses tumores malignos são diferentes dos vírus individuais conhecidos (como o vírus Epstein-Barr, herpes humano) (Freitas et al., 2017).

$\mathrm{O}$ vírus da imunodeficiência humana é um lentivírus pertencente à família Ortopenirinae da família dos retrovirais. O principal alvo do HIV é o sistema imunológico, principalmente os linfócitos T CD4 +. Resumindo, a infecção pelo HIV se desenvolve de forma gradual e silenciosa. Após uma infecção aguda (inicial), o vírus se replica em grande número e se espalha para os tecidos linfáticos, no período assintomático (atualmente denominado "crônico") ocorre ativação imunológica contínua e alta replicação viral. Nos estágios mais avançados, devido à presença de infecções oportunistas e / ou cânceres, os linfócitos T CD4 + são significativamente depletados, levando à síndrome da imunodeficiência adquirida (Cruz, 2020).

A infecção pelo vírus HIV pode ser transmitida através do contato com sangue, sêmen, lubrificação vaginal ou leite materno. O HIV está presente nesses fluidos corporais tanto na forma de partículas livres como em células do sistema imunológico infectadas. As principais vias de transmissão são as relações sexuais sem proteção, o compartilhamento de seringas contaminadas e a transmissão entre mãe e filho durante a gravidez ou amamentação. O risco de transmissão através da saliva é mínimo (Pinto Neto et al., 2021).

O câncer acomete aproximadamente $50 \%$ dos indivíduos infectados com o vírus da imunodeficiência adquirida, que é uma parte considerável da carga de doença acessível e da morte patológica. A definição de câncer infeccioso marca o início da imunossupressão clinicamente relevante e é causada pela perda do controle imunológico de infecções virais carcinogênicas. Essas infecções são muito comuns, especialmente antes da introdução da terapia antirretroviral. Os mais comuns são sarcoma de 
Kaposi, linfoma não Hodgkin e câncer cervical (Costa et al., 2020).

O linfoma é um tumor maligno do sistema linfático, que se caracteriza pela proliferação clonal de linfócitos B ou T / NK maduros ou imaturos, e está em diferentes estágios de diferenciação, manifestando-se clinicamente como linfonodo e / ou doença extranodal. De acordo com a morfologia, imunofenótipo, diferenças moleculares e clínicas, são geralmente divididos em duas categorias: Linfoma de Hodgkin (LH) e Linfoma não Hodgkin (LNH) (Lacet, 2020).

O linfoma maligno é uma doença neoplásica agressiva em que seu sistema linfático cresce rapidamente. Se não for tratado a tempo, pode levar à morte em semanas ou meses. Em comparação com a população em geral, todos os tipos de linfoma têm um impacto muito mais significativo nos pacientes com HIV. No entanto, o linfoma não-Hodgkin de células B é considerado um dos mais comuns. O Linfoma não-Hodgkin sistêmico relacionado ao HIV (LNH-HIV) é quase sempre altamente maligno e tem um prognóstico bastante ruim (Fonseca Marrero et.,2019).

O linfoma ocorre devido à aquisição gradual de DNA, incluindo mutações, amplificação ou deleção de genes e translocações cromossômicas. Essas alterações geralmente ocorrem em linfonodos, mas podem ocorrer em quase todos os tecidos. O LNH representa um grupo com diferentes tipos de câncer, muitos dos quais são derivados de linfócitos B maduros e alguns são derivados de linfócitos T ou linfócitos NK. Em todos os casos, células maduras e células precursoras podem estar envolvidas (Lima, 2019).

Indivíduos infectados com HIV apresentam alto risco de LNH e SK. Na Europa, entre 1994 e 2000, a prevalência de SIDA relacionada ao LNH aumentou de 3,6\% para 5,4\%. Desde a introdução da terapia anti-retroviral, a incidência de certos tipos de LNH diminuiu. Desde o início dos anos 1980, os linfomas cerebrais primários (incluindo o linfoma de Burkitt e o linfoma imunoblástico) foram classificados como doenças relacionadas à SIDA. A maioria das pessoas infectadas pelo HIV descobre que são soropositivas durante o tratamento do LNH e SK em que não apresentam manifestações clínicas de SIDA (Petroianu et al., 2020).

Em uma análise do banco de dados do National Cancer Center, a sobrevida geral média desses pacientes é de 3 a 6 meses. Cerca de 50\% dos pacientes infectados com LNH e HIV morrem de infecções oportunistas, enquanto os outros 50\% morrem em decorrência da progressão ou recorrência da doença linfocítica (Rodrigues et al., 2019).

Infecções oportunistas e tumores são os fatores decisivos para a SIDA. Dentre as infecções oportunistas, destacam-se: cistos pulmonares, neurotoxoplasmose, tuberculose atípica ou difusa, meningite criptocócica e retinite por citomegalovírus. Os tumores mais comuns em mulheres jovens são linfoma não-Hodgkin, sarcoma de Kaposi (SK) e câncer cervical. Nestes casos, a contagem de LT-CD4 + é inferior a 200 células / mm3 na maioria dos casos (Lopes et al., 2019).

O linfoma não-Hodgkin (LNH) é o segundo tipo de câncer mais comum em pacientes positivos para o vírus da imunodeficiência humana (HIV). A frequência de ocorrência de LNH é diretamente proporcional à progressão natural da imunossupressão e à diminuição na contagem de linfócitos CD4 após a infecção pelo HIV. Além disso, apesar do advento da terapia antirretroviral, a incidência desse câncer não diminuiu. O prognóstico de pacientes sorológicos para HIV com LNH é ruim, e o tempo médio de sobrevida após o diagnóstico é de cerca de 1 ano (Rodrigues et al., 2019).

A linfopenia causada pela ação do vírus HIV é uma estimulação para medula óssea, em uma tentativa de reverter à imunossupressão e estimular a produção de linfócitos. Ela se baseia na interação entre células CD3 e células CD4 + infectadas, de modo a resultar na exaustão e na falha na produção das novas células B, o que leva a distúrbios hematopoiéticos em que se associa ao volume celular aumentado de células precursoras na medula óssea, aumentando a possibilidade de erros genéticos e da incidência de linfoma em pacientes HIV + (Da Silva Araújo et al.,2021). 
Research, Society and Development, v. 10, n.5, e55610515203, 2021

(CC BY 4.0) | ISSN 2525-3409 | DOI: http://dx.doi.org/10.33448/rsd-v10i5.15203

\section{Conclusão}

O HIV é considerado um problema de saúde pública mundial há décadas. Quando não há tratamento com terapias antirretrovirais ocorre um distúrbio em que o sistema imunológico dos pacientes é suprimido, desenvolvendo a SIDA. Diversos estudos mostram a associação desta síndrome com infecções oportunistas e canceres em consequência das falhas recorrentes do sistema imune desses pacientes. Um dos canceres mais comuns associados a SIDA é o linfoma não-Hodgkin, uma neoplasia que afeta o sistema linfático dos pacientes e que apresenta um prognóstico ruim e uma expectativa de vida baixa para esses pacientes.

É bastante comum pacientes com SIDA com manifestações clínicas inespecíficas não realizem o tratamento e só descobrirem a infecção durante o tratamento para os linfomas. É necessário o desenvolvimento de mais estudos científicos a cerca deste tema, e a busca constante de novos tratamentos em busca de qualidade e expectativa de vida maior para esses pacientes, sempre enfatizando a importância da prevenção para a não contaminação pelo vírus e buscando incluir esses portadores na sociedade e nas terapias antirretrovirais.

\section{Referências}

Costa, L. D. L. N., Kennelly, A. S., de Souza, D. A. C., \& de Lima, U. R. S. (2020). Risco de Câncer em Pacientes que Vivem com HIV/Aids: Revisão Sistemática. Revista Brasileira de Cancerologia, 66(4), e-041053.

Cruz, C. F. F. (2019). Cancro e terapêutica prolongada com ART em indivíduos soropositivos com HIV (Doctoral dissertation).

Da Silva Araújo, S., Monteiro, C. G. F., Sampaio, T. L., \& de Albuquerque Oliveira, A. (2021). Linfoma de Hodgkin em Pacientes HIV Positivo em Uso de Antirretrovirais de Alta Efetividade. Revista Brasileira de Cancerologia, 67(2), e-09825.

Fonseca Marrero, C. A., Ávila Cabreja, J. A., Fonseca Gómez, C. M., Larrea Fabra, R. R., Mederos Hernández, J., \& Fernández Massip, H. (2019). Atypical presentation of non-Hodgkin's lymphoma in a patient with AIDS. Revista Cubana de Medicina Tropical, 71(2), 1-11.

Freitas, J. B., Gagliani, L. H., Caseiro, M. M., \& Pierre, A. P. V. R. (2017). Perfil epidemiológico dos pacientes infectados pelo HIV com e sem câncer em um hospital publico na baixada Santista-SP-Brasil. UNILUS Ensino e Pesquisa, 14(34), 17-24.

Lacet, D. F. R. (2020). Qual o significado clínico-patológico da imunoexpressão de CD20 no linfoma de Hodgkin clássico? (Doctoral dissertation).

Lima, N. M. R. (2019). Uso de inibidores PI3K no tratamento do linfoma não-Hodgkin: uma revisão concisa. (Trabalho de Conclusão de Curso), Universidade de Brasília.

Lopes, A. O. L. (2019). Aspectos epidemiológicos e clínicos de pacientes infectados por HIV. Brazilian Journal of Clinical Analyses, 51 (4), 296-9.

Petroianu, A., Alberti, L. R., Orsi, V. L., Viana, F. C. T., \& Moura, C. B. (2020). Comparação etiopatogênica, epidemiológica e clinicoterapêutica de linfoma não Hodgkin e sarcoma de Kaposi. ABCD. Arquivos Brasileiros de Cirurgia Digestiva, São Paulo, 33(2), e-1521.

Pinto Neto, L. F. D. S., Perini, F. D. B., Aragón, M. G., Freitas, M. A., \& Miranda, A. E. (2021). Protocolo Brasileiro para Infecções Sexualmente Transmissíveis 2020: infecção pelo HIV em adolescentes e adultos. Epidemiologia e Serviços de Saúde, 30, e-2020588.

Rodrigues, I. B. P., de Lima, G. C., Félix, M. R., de Paula Sousa, L., \& de Andrade, R. G. M. (2019). Linfoma plasmablástico em paciente com infecção pelo vírus da imunodeficiência humana. Brasília Med, 56, 45-47. 